\title{
"I will survive": Online streaming and the chart survival of music tracks
}

\author{
Daniel Kaimann $^{1}$ () | Ilka Tanneberg ${ }^{1}$ | Joe Cox $^{2}$ ()
}

${ }^{1}$ Department of Management, Paderborn University, Paderborn, Germany

${ }^{2}$ Faculty of Business, Athabasca University, Athabasca, AB, Canada

\section{Correspondence}

Daniel Kaimann, Department of Management, Paderborn University, 33098 Paderborn,

Germany.

Email: daniel.kaimann@uni-paderborn.de

Funding information

German Research Foundation (DFG), Grant/

Award Number: 160364472-SFB901
Digital streaming has had a profound effect on the commercial music sector and now accounts for $80 \%$ of industry revenues in the United States. This study investigates the consumption of music on digital streaming platforms by analyzing the factors affecting the chart survival of individual music tracks. Our data are taken from the Spotify Global Top 200 between January 2017 and January 2020, containing observations on 3,007 unique tracks by 642 artists over 1,087 days. We identify a number of unique consumption traits applicable to online streaming services, which we use to explain variations in chart longevity. We find a positive association between the amount of time a track spends in the chart and the involvement of a major label. We also find that the level of competition from other chart entries, as well as some elements related to the pattern of diffusion, associates significantly with the likelihood of chart survival. The study highlights several important managerial implications for key industry stakeholders.

\section{1 | INTRODUCTION}

Digitalization has had a considerably disruptive influence on the commercial music market over the course of the last 20 years. During this time period, the music industry has witnessed a steady decline in traditional sales and distribution processes (Naveed, Watanabe, \& Neittaanmäki, 2017), coupled with the introduction of a diverse range of new forms of consumption (Borghi, Maggiolino, Montagnani, \& Nuccio, 2012). Online streaming platforms now represent one of the most significant distribution channels for recorded music, accounting for more than half of industry revenues worldwide (International Federation of the Phonographic Industry, 2020) and as much as $80 \%$ of revenues in the United States (Recording Industry Association of America, 2019). Despite the significantly disruptive effect of streaming services, relatively little research has been undertaken in relation to the consumption of music via these online channels. Among the limited number of studies that do investigate this topic, several have focused on estimating the "cannibalization" effect that digital streaming has had upon the sales of physical media (Aguiar \&
Waldfogel, 2018; Hiller, 2016; Koukova, Kannan, \& Ratchford, 2008). However, given the prominence of online streaming platforms, there remains a need for music labels to better understand how to attract and retain the attention of listeners in such settings (Ren \& Kauffman, 2018, p. 14).

Our study contributes towards addressing this need by exploring issues related to the consumption of music via online streaming platforms. The aim of our study is to investigate factors affecting the survival of individual tracks on the chart of the most popular tracks featuring on Spotify, the world's leading music streaming platform (Mulligan, 2018). It is widely recognized that charts serve as a consistent barometer of music appeal (Gloor, 2011) and thus function as an important "market information regime" for industry stakeholders (Steininger \& Gatzemeier, 2019). For example, music labels have been suggested to attach significant weight to chart performance data as part of an increasingly selective approach to identifying and signing new talent (Benner \& Waldfogel, 2016). Investors have also been shown to use chart data as a means to update their expectations on commercial performance, such that chart positions can have a direct

This is an open access article under the terms of the Creative Commons Attribution-NonCommercial-NoDerivs License, which permits use and distribution in any medium, provided the original work is properly cited, the use is non-commercial and no modifications or adaptations are made.

(c) 2020 The Authors. Managerial and Decision Economics published by John Wiley \& Sons Ltd 
influence on the share prices of music labels (Mehrafshan, Goerke, \& Clement, 2016).

Recent evidence has also highlighted how charts are highly valued by music consumers. Chart tracks benefit from increased visibility and associated reductions in search costs (Essling, Koenen, \& Peukert, 2017; Yoo \& Kim, 2012). As a result, charts have been found to represent one of the main discovery tools available to users of streaming platforms (Tang \& Yang, 2017). Chart presence also serves as a signal of quality, which can attract additional consumers as a result of bandwagon effects (Connolly \& Krueger, 2006; Moe \& Earl, 2009) and also increase the likelihood of repeat consumption (Im, Song, \& Jung, 2019, p. 175). This latter point is particularly relevant given that streaming royalties are received on a per-play basis, which attaches even greater importance to achieving a "hit" than conventional sales channels do (Hiller \& Walter, 2017). Altogether, achieving and maintaining a high chart ranking have been widely shown to represent a vitally important aspect of commercial success in the music industry. Our study contributes towards developing a better understanding of digital streaming charts by addressing the following research question: What are the factors that affect the survival of an individual track within digital streaming charts?

Among previous studies of the chart performance and survival of recorded music (see, e.g., Strobl \& Tucker, 2000; Bhattacharjee, Gopal, Lertwachara, Marsden, \& Telang, 2007; Asai, 2009; Hendricks \& Sorensen, 2009; Elberse, 2010; Elliott \& Simmons, 2011), few to our knowledge have investigated the phenomenon in the context of digital streaming. Among those that do, Ren and Kauffman (2017) analyze the popularity of tracks streamed via the online platform LastFM over the period 2005-2015. The authors find semantic constructs such as genre to be the most important determinant of popularity for any given music track, which is also shown to increase with the volume of recent output released by each artist. The study also finds that tracks tend to remain popular longer when they debut at a higher chart rank, whereas major record labels are found to have no effect on chart longevity.

Another recent publication by Im, Song, and Jung (2018) models digital chart survival time using data from a Korean music streaming platform, covering the period 2011-2013. The study finds evidence that a higher debut rank, tie-ins with other media (e.g., movie soundtracks), and album title tracks are associated most strongly with longer chart survival times. However, it is notable that the authors sole focus on data from a Korean platform limits the generalizability of their findings. In addition, the study uses data from the first part of the decade when streaming services were still in a relatively early stage of development, given that streaming revenues did not become the most significant source of revenue for the U.S. music industry until 2015 (Hiller \& Walter, 2017).

Both of the aforementioned studies are further limited by the way in which they account for competition faced by individual tracks released during a similar period. Ren and Kauffmann (2017) do not control for any measures of competition, whereas Im et al. (2018) measure competition in terms of the number of tracks released over the course of an entire calendar year.
Our study addresses these limitations in a number of ways. First, we capture data from the Spotify chart over the period from January 2017 through January 2020. By using recent, worldwide data from the Spotify platform, our results can be considered more representative of the pattern of global music consumption in the digital era in comparison with other studies. Second, we uniquely utilize a dataset containing detailed information on the number of competitor tracks within the Spotify charts released during the same week by the same and other artists, thereby accounting for dynamic elements of chart competition that have not featured in other studies. Understanding these consumption patterns is of vital importance for many stakeholders in the commercial music sector, including streaming platforms, artists, and record labels. We also examine the effects of other factors that have not been explored in previous studies, such as the time between the initial release and chart debut.

The remainder of this study is structured as follows. Section 2 outlines the effect that online streaming has had upon the music industry, leading to the development of a set of hypotheses related to the determinants of demand for digital music products in Section 3. Section 4 provides more information about our data and modeling approach, and our results are presented in Section 5. Finally, a discussion of our most important findings and an overall conclusion to the study are presented in Sections 6 and 7, respectively.

\section{2 | ONLINE STREAMING AND THE MUSIC INDUSTRY}

Online streaming platforms such as Spotify and Pandora have risen considerably in popularity during recent years, granting users unlimited on-demand access to vast catalogs of digital music as a temporary experience without permanent ownership (Hiller \& Walter, 2017). Following the growth of these online streaming platforms, global music industry revenues have risen over the last four consecutive years, with an increase of $8.2 \%$ having been observed between 2018 and 2019 alone (International Federation of the Phonographic Industry, 2020). It has been suggested that one of the reasons why digital streaming platforms have improved the commercial prospects of the industry is that they represent a credible legal alternative to piracy (Thomes, 2013), largely due to their flat-rate pricing and opportunities for consumption in social groups (Dörr, Wagner, Hess, \& Benlian, 2013).

The introduction of online streaming services has significantly disrupted the supply side of the commercial music market. Digital music, in common with other information goods, has a replication and distribution cost that is close to zero (Zwass, 2003). Digital technologies have further reduced the fixed costs associated with the production of new music, as well as with its promotion via social media and other online channels (Waldfogel, 2015). In aggregate, these changes have led to a fundamental reduction in the value of specific assets held by record labels, which were once the principal source of their competitive advantage (Clemons \& Lang, 2003). Some authors have therefore questioned the extent to which record labels will be able to 
prosper in the new digital environment (Huang, 2005). Bricks-andmortar retail institutions also face a considerable threat from digital platforms (Bockstedt, Kauffman, \& Riggins, 2006). By circumventing the constraints imposed by physical sales and distribution channels, music streaming services allow consumers to enjoy a virtually instantaneous adoption of music products (Graham, Burnes, Lewis, \& Langer, 2004). Thus, the process of digitalization has led to a more rapid uptake of new material in commercial music markets due to the speed and convenience of access (Hendricks \& Sorensen, 2009).

Further, in common with retailers of other digital products, online streaming services have effectively utilized bundling strategies as a means of maximizing revenues. The industry has historically used the album format as a means of bundling commercial music output. However, the vast catalog of material offered by streaming platforms, along with the capacity for consumers to build their own unique combinations of tracks, calls into question the viability of traditional approaches to product bundling (Bockstedt et al., 2006). In particular, the extent to which the album format remains an effective means of bundling in the digital era is further limited by the storage capacity of physical media (e.g., records, cassette tapes, or CDs). The absence of such constraints, coupled with high release rates and slow obsolescence, allows digital streaming platforms to bundle together enormous quantities of materials (Clemons \& Lang, 2003). The bundling of products on such a large scale affords opportunities to benefit from economies of aggregation in price setting, whereby sellers of digital products are better able to predict consumer willingness to pay for a bundle of goods in comparison with individual component products (Bakos \& Brynjolfsson, 2000). Under these conditions, sellers are more likely to set optimal prices and thus maximize profits.

Although product bundling may be revenue enhancing for streaming platforms, large catalogs of content have the potential to impose (significant) search and filtering costs upon consumers. Because recorded music demonstrates the characteristics of an experience good, opportunities for product sampling are likely to be highly valued by consumers (Li, Jain, \& Kannan, 2019; Tu \& Lu, 2006). Online music streaming services help to reduce search and sampling costs partly by providing playlists of popular tracks (including charts), as well as by using sophisticated algorithms to recommend new artists or songs on the basis of observed preferences and behaviors (Che \& Hörner, 2017). This feature also allows streaming platforms to benefit from network effects (Chen \& King, 2017; Ren \& Kauffman, 2018) by sharing customized playlists and allowing users to observe the consumption habits of friends.

Taken together, these characteristics of digital streaming platforms are likely to have a significant impact upon the nature of music consumption. Fundamental technological changes and the reduction in production and distribution costs have the potential to undermine the market power of large record labels. Additionally, the enormous volume of content available to consumers has almost inevitably affected the nature of competition between individual music tracks vying for a finite amount of listener attention. Further, a combination of instantaneous distribution channels and the ease with which consumers can find and access new tracks is also likely to have had an impact upon the diffusion pattern of new and niche products. In the following section, we extend and develop each of these arguments with a view towards developing a set of formal research hypotheses.

\section{3 | RESEARCH HYPOTHESES}

We argue that digital streaming platforms have significantly disrupted the music industry and have resultantly affected a number of key determinants of consumption, namely, major labels, chart competition, and diffusion. We propose that these factors, alongside control variables such as specific artist and track characteristics, are likely associated with variations in chart longevity for individual music tracks consumed via online streaming platforms.

\section{1 | Major labels}

Labels have traditionally played a crucial role in the conventional model of music production, overseeing the recording, manufacturing, marketing, and distribution processes (Graham et al., 2004). The significant costs associated with these actions have tended to result in relatively high entry barriers, as well as in a high level of concentration on the supply side (Alexander, 1994). Resultantly, the three largest music labels (Universal, Warner, and Sony) have enjoyed an effective monopoly over the commercial music business (Mulligan, 2015), and their market power allows them to strongly influence a wide range of industry activities (Bhattacharjee et al., 2007). For example, releases from major labels have been shown to remain in the charts of physical media sales for longer periods in comparison with independents, due to their ability to exploit superior distribution and marketing channels (Strobl \& Tucker, 2000).

Despite the historical dominance of major labels, the transition to digital distribution has fundamentally changed the power structure in music markets as a result of the decoupling of value creation from revenue processes (Clemons \& Lang, 2003; Moreau, 2013). Consequently, barriers to entry in the market for recorded music have fallen, which has disproportionately benefited niche artists (Brynjolfsson, $\mathrm{Hu}$, \& Simester, 2011). As a result, products released via independent labels are enjoying greater representation among lists of bestselling tracks on digital platforms (Waldfogel, 2015), and these labels now earn a majority of their revenue from such channels (WINTEL, 2017).

However, despite the challenges and threats to market dominance posed by online streaming services, major labels continue to outperform others in terms of album and track sales (Klein, Meier, \& Powers, 2017). Even facing challenges to their traditional functions in the value chain of commercial music, major labels are still likely to play a significant role in terms of development, marketing, and promotion that artists may not be able to provide for themselves (Bockstedt et al., 2006). We therefore contend that the support and resources offered by major labels will tend to increase demand for a given music track relative to independents. These arguments lead us to develop our first research hypothesis, namely 
H1. : The backing of a major label associates positively with the chart longevity of a given music track.

\section{2 | Chart competition}

Digital streaming has been found to be associated with a greater diversity and variety of material than other music markets (Datta, Knox, \& Bronnenberg, 2018). Online platforms offer niche products new opportunities to capture a share of the long tail of market demand, with the popularity of such products having been shown to increase with the volume and quantity of the product assortment, as well as with the presence of recommender systems (Hinz, Eckert, \& Skiera, 2011). Lang, Shang, and Vragov (2015) also show that niche products particularly benefit from the opportunities for cocreation afforded by the customizable and sharable playlists that are a feature of online streaming platforms. Customizable playlists further allow consumers to "cherry-pick" the best outputs from a wide range of artists and avoid unfavorable content (Gopal, Ramesh, \& Whinston, 2003). This consideration is particularly relevant given that different tracks released by the same artist may not be valued equally by consumers (Bhattacharjee, Gopal, Lertwachara, \& Marsden, 2006) and a majority of albums tend to contain only a limited number of high-quality tracks (Smith \& Wingfield, 2008). As a result of these factors, digital streaming platforms may lead to increased competition between the outputs of a given artist, which has the potential to undermine the viability of the album format as a means of output bundling (Elberse, 2010).

Taking the arguments and evidence outlined above into account, we argue that an individual track appearing in a digital streaming chart faces competition from other chart tracks released at the same time. This chart competition arises not only from chart tracks released by other artists ("external chart competition") but also from other chart tracks released at the same time by the same artist ("internal chart competition"). We therefore propose our second research hypothesis, namely

H2. The intensity of external and internal chart competition associates negatively with the chart longevity of a given music track.

\section{3 | Diffusion}

The pattern of diffusion for digital music is likely to be substantially different to that observed in conventional markets. A number of studies have argued that the low sampling cost associated with digital consumption channels results in a more pronounced concentration of demand in the period immediately following release (Asai, 2009; Rangaswamy \& Gupta, 2000). As a result, music released via digital channels is likely to experience shorter chart survival times and higher turnover rates in comparison with physical media (Bhattacharjee et al., 2007; Klein \& Slonaker, 2010; Ordanini \& Nunes, 2016). On the other hand, it is possible that tracks will experience a slower decline in chart position over time on streaming platforms than conventional music markets, due to fundamental differences in the way that music is consumed. The sale of physical media is recorded only once at the point of purchase, meaning that chart performance is unaffected by the number of times each consumer subsequently listens to the product. However, digital streaming works differently in that platforms measure chart positions on the basis of the number of times each individual track is streamed. As a result, chart performance can be affected by repeat consumption (Datta et al., 2018).

Our study contributes to resolving these ambiguities by examining how the diffusion of new music tracks on digital streaming platforms affects chart survival times. One of the ways we measure the diffusion of a music track is in terms of its debut rank. A number of studies have shown how early success is likely to have a disproportionately positive influence on chart positions as a result of perpetuating bandwagon effects and associated herding behaviors (Bhattacharjee et al., 2007; Moe \& Earl, 2009; Strobl \& Tucker, 2000). Im et al. (2018) have also shown that this same pattern exists for music released on digital streaming platforms. Tracks that reach higher positions in streaming charts have also been shown to receive many additional "residual" streams as they fall down the rankings, whereas the same benefit is not enjoyed by tracks that debut at lower positions (Hiller \& Walter, 2017). Altogether, empirical evidence from the research literature suggests that the initial performance of a music track is likely to have a significantly positive effect on chart performance and may even be more pronounced on digital streaming platforms than in conventional music markets.

Although a number of studies have commented on the effect of debut rank on chart longevity, less evidence exists on the time taken to reach the chart in the first place. On the one hand, tracks that take longer to enter the charts may represent "slow burners" that build a loyal audience over time and resultantly spend a longer time in the charts following their initial entry (see Ordanini, 2006, for a general discussion). On the other hand, tracks that start slowly may be unlikely to experience a subsequent surge in demand, given that modern music has been shown to typically perform well in the charts either immediately or not at all (Schneider \& Gros, 2019). Few (if any) studies on chart performance present empirical evidence on this issue; hence, our study addresses an important gap in knowledge in this regard. On the basis of the arguments outlined above, suggesting a concentration of sales activity for new music in the period immediately following its release, we contend that it is more likely that tracks that enter the streaming charts more quickly and at a higher initial position will tend to remain there for longer periods in comparison with those that enter the charts more slowly and/or at a lower position

Taken together, the arguments put forward in this section lead to the development of our third research hypothesis, which is as follows:

H3. Quicker and higher initial entry will be associated positively with the chart longevity of a given music track. 


\section{DATA AND MODEL}

To empirically test our three hypotheses related to the demand for music and the characteristics of digital streaming platforms, we use spotifycharts.com to construct a sample consisting of 3,802 music tracks from 838 artists and their daily streaming performance on the Spotify Global Top 200 chart between January 2017 and January 2020. An issue affecting the modeling of chart survival time is that 634 of the tracks appearing in our data were released before the beginning of the sample period, whereas 161 survive in the charts after the period's conclusion. Consequently, our analysis must contend with the issue of left and right censoring (see Wooldridge 2013, p. 609). Left censoring appears when the event of interest has already occurred before enrollment, whereas right censoring appears when a subject leaves the study before an event occurs or the study ends before the event has occurred. Consistent with other studies of chart survival (Bhattacharjee et al., 2007; Ren \& Kauffman, 2017), we remove these observations from our dataset to address the issues associated with the use of censored data. Following this approach, we base our analysis of chart survival time on a subset of data comprising 3,007 tracks from 642 different artists (e.g., the song "Old Town Road" by Lil Nas X feat. Billy Ray Cyrus appeared in the chart for a period of 112 days from April 5, 2019, to July 25, 2019).

Our dependent variable is a measure of the cumulative amount of time (in days) that an individual track spends on the Spotify Global Top 200 chart, calculated on a daily basis from the time of the track's initial chart entry to the point of exit. Therefore, our survival time variable is a continuous counting variable of the days a song stays in the chart. If a track drops out, the survival variable stops counting and starts again after the track re-enters (as per Blossfeld, Golsch, \& Rower, 2009). To address the issue of observational gaps of tracks that may leave and re-enter the Spotify charts, we include a binary variable indicating a song re-entry after its previous chart dropout. A kernel density function for our dependent variable is presented in

Figure 1. It can clearly be seen that the distribution of chart survival

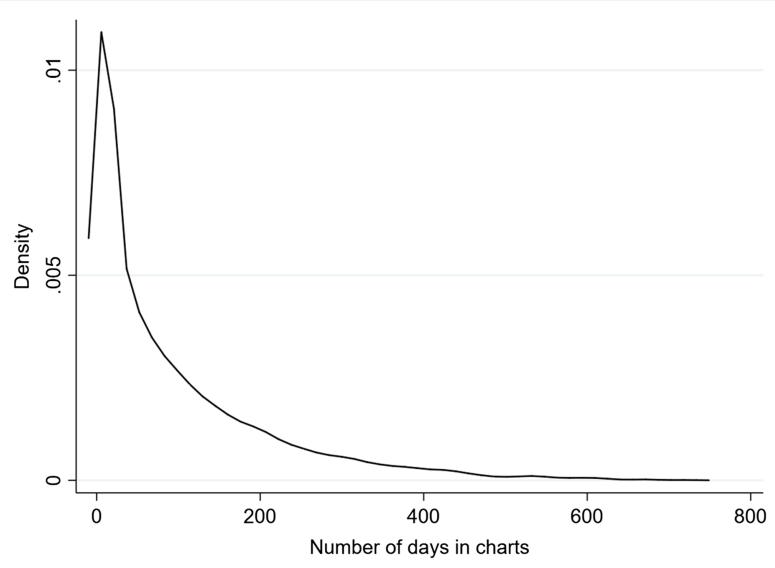

FIGURE 1 Kernel density distribution of the amount of days the individual songs are listed in the Spotify Global Top 200 charts [Colour figure can be viewed at wileyonlinelibrary.com] time is relatively long-tailed, suggesting a disproportionately small number of tracks that survive for long periods (in excess of 400 days). The survival curve presented in Figure 2 confirms this relationship. Around $50 \%$ of tracks leave the chart after a period of 8 days, whereas $75 \%$ of tracks drop out after 42 days.

Summary and descriptive statistics for all variables used in our empirical analysis can be found in Table 1. All data on streaming volumes and chart positions are obtained directly from Spotify charts, whereas other song and artist characteristics (e.g., release date, genre, gender, experience, and previous success) are obtained either from the Spotify, Kworb, or AllMusic databases.

As stated in the research hypotheses section, we test the effect of three different music consumption related factors on the demand for music tracks, namely, labels, chart competition, and diffusion. We measure the effect of major music labels (i.e., Sony Music, Universal Music, and Warner Music) versus independents on demand using the dummy variable "Major Label." To classify labels into these dichotomous terms, we use a list of sublabels that are officially related to one of the major labels presented in Table 2. According to the data in Table 1, it is apparent that a significant majority of tracks appearing in the Spotify Top 200 chart (around 93\%) are released through labels affiliated with the majors, with only around $7 \%$ released by true independents.

Our study includes two measures of chart competition that account for the number of other tracks released during the same week that also appear in the Spotify Global Top 200 charts. We measure chart competition both in terms of the number of new chart releases from other artists ("external chart competition") and by the same artist ("internal chart competition"). More specifically, external chart competition measures the number of weekly new Top 200 chart appearances from other artists if their chart appearances occurred in the release week. Accordingly, internal chart competition measures the number of weekly new Top 200 chart appearances from the same artist if his or her chart appearances occurred in the release week. Although we are not able to measure external competition from tracks

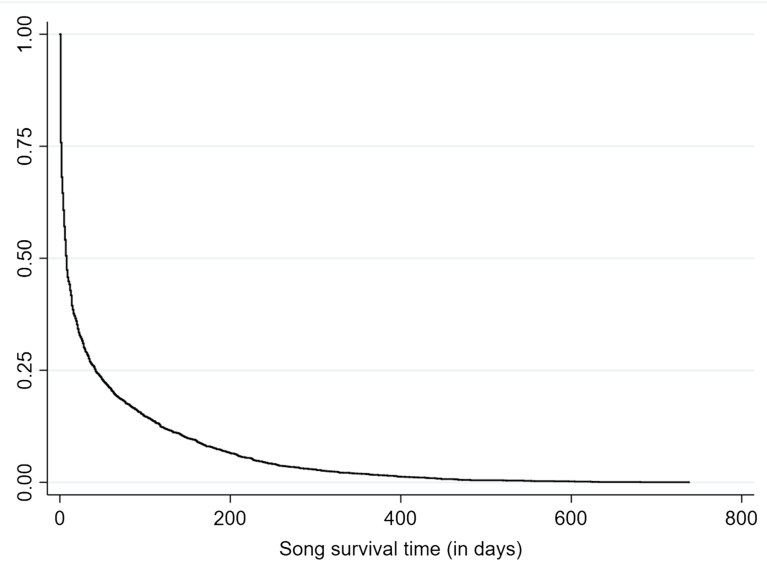

FIGURE 2 Survival function of the total time a song is in the Spotify Global Top 200 streaming charts (in days) [Colour figure can be viewed at wileyonlinelibrary.com] 
TAB LE 1 Descriptive statistics for variables used in the analyses

\begin{tabular}{|c|c|c|c|c|c|c|c|}
\hline Variable & Description & Source & Observation & $M$ & $S D$ & Min & Max \\
\hline \multicolumn{8}{|c|}{ Dependent variable } \\
\hline $\begin{array}{l}\text { Song survival } \\
\text { time }\end{array}$ & $\begin{array}{l}\text { Total time a song is in the chart (in } \\
\text { days). }\end{array}$ & Spotify Charts & 31,137 & 93.407 & 114.752 & 1 & 738 \\
\hline \multicolumn{8}{|c|}{ Independent variables } \\
\hline Major label & $\begin{array}{l}\text { Binary variable indicating a major label } \\
\text { (Sony, Universal or Warner). }\end{array}$ & Spotify API & 31,137 & 0.928 & 0.258 & 0 & 1 \\
\hline $\begin{array}{r}\text { External chart } \\
\text { competition }\end{array}$ & $\begin{array}{l}\text { Weekly number of newly Spotify } \\
\text { Global Top } 200 \text { chart appearances } \\
\text { from other artists without observed } \\
\text { song. }\end{array}$ & Spotify Charts & 31,137 & 21.671 & 9.897 & 0 & 49 \\
\hline $\begin{array}{l}\text { Internal chart } \\
\text { competition }\end{array}$ & $\begin{array}{l}\text { Weekly number of newly Spotify } \\
\text { Global Top } 200 \text { chart appearances } \\
\text { from the same artist without } \\
\text { observed song. }\end{array}$ & Spotify Charts & 31,137 & 0.804 & 3.009 & 0 & 24 \\
\hline Start position & $\begin{array}{l}\text { A song's starting position by first } \\
\text { appearance in the Spotify Global Top } \\
200 \text { chart. }\end{array}$ & Spotify Charts & 31,137 & 100.610 & 67.940 & 1 & 200 \\
\hline Time to charts & $\begin{array}{l}\text { Days between release date and first } \\
\text { appearance in the Spotify Global Top } \\
200 \text { chart. }\end{array}$ & $\begin{array}{l}\text { Release date } \\
\text { from Spotify } \\
\text { API }\end{array}$ & 31,137 & 19.015 & 66.553 & 0 & 755 \\
\hline \multicolumn{8}{|c|}{ Product-specific controls } \\
\hline \multicolumn{8}{|l|}{ Genre } \\
\hline Country & $\begin{array}{l}\text { Binary variable indicating the song } \\
\text { genre "Country". }\end{array}$ & AllMusic.com & 31,137 & 0.006 & 0.077 & 0 & 1 \\
\hline$R \& B$ & $\begin{array}{l}\text { Binary variable indicating the song } \\
\text { genre "R\&B". }\end{array}$ & AllMusic.com & 31,137 & 0.038 & 0.192 & 0 & 1 \\
\hline Rap & $\begin{array}{l}\text { Binary variable indicating the song } \\
\text { genre "Rap". }\end{array}$ & AllMusic.com & 31,137 & 0.352 & 0.478 & 0 & 1 \\
\hline Miscellaneous & $\begin{array}{l}\text { Binary variable indicating the song } \\
\text { genre "Miscellaneous," including } \\
\text { Blues, Classical, Reggae, Religious, } \\
\text { and Stage\&Screen. }\end{array}$ & AllMusic.com & 31,137 & 0.005 & 0.071 & 0 & 1 \\
\hline Soundtrack & $\begin{array}{l}\text { Binary variable indicating if album/track } \\
\text { name include words "soundtrack," } \\
\text { "motion," "from," or genre includes } \\
\text { the word "screen." }\end{array}$ & Spotify Charts & 31,137 & 0.019 & 0.137 & 0 & 1 \\
\hline Remix & $\begin{array}{l}\text { Binary variable indicating if track name } \\
\text { includes word "remix." }\end{array}$ & Spotify Charts & 31,137 & 0.032 & 0.176 & 0 & 1 \\
\hline Christmas & $\begin{array}{l}\text { Binary variable indicating if album/track } \\
\text { name include words "Christmas," } \\
\text { "snowman," or "Holiday." }\end{array}$ & Spotify Charts & 31,137 & 0.003 & 0.054 & 0 & 1 \\
\hline Compilation & $\begin{array}{l}\text { Binary variable indicating if the song is } \\
\text { streamed from a compilation. }\end{array}$ & Spotify API & 31,137 & 0.009 & 0.094 & 0 & 1 \\
\hline Single & $\begin{array}{l}\text { Binary variable indicating if the song is } \\
\text { streamed from a single. }\end{array}$ & Spotify API & 31,137 & 0.477 & 0.499 & 0 & 1 \\
\hline
\end{tabular}


TABLE 1 (Continued)

\begin{tabular}{|c|c|c|c|c|c|c|c|}
\hline Variable & Description & Source & Observation & $M$ & $S D$ & Min & Max \\
\hline \multirow{2}{*}{\multicolumn{8}{|c|}{ Artist-specific controls }} \\
\hline & & & & & & & \\
\hline Band & $\begin{array}{l}\text { Binary variable indicating if the song is } \\
\text { performed by a band. }\end{array}$ & AllMusic.com & 31,137 & 0.092 & 0.290 & 0 & 1 \\
\hline Duo & $\begin{array}{l}\text { Binary variable indicating if the song is } \\
\text { performed by a duo. }\end{array}$ & AllMusic.com & 31,137 & 0.044 & 0.205 & 0 & 1 \\
\hline Female & $\begin{array}{c}\text { Binary variable indicating if the song is } \\
\text { performed by a female solo artist. }\end{array}$ & AllMusic.com & 31,137 & 0.186 & 0.389 & 0 & 1 \\
\hline Male & $\begin{array}{c}\text { Binary variable indicating if the song is } \\
\text { performed by a male sola artist. }\end{array}$ & AllMusic.com & 31,137 & 0.678 & 0.467 & 0 & 1 \\
\hline Experience & $\begin{array}{l}\text { Difference between actual year of } \\
\text { observation and first appearance in } \\
\text { music industry. }\end{array}$ & AllMusic.com & 31,137 & 12.620 & 6.711 & 7 & 50 \\
\hline $\begin{array}{l}\text { Previous } \\
\text { success }\end{array}$ & $\begin{array}{l}\text { Number of songs of an artist in the } \\
\text { Spotify Global Top } 200 \text { chart since } \\
\text { October } 2014 \text { before an observed } \\
\text { song enters the chart. }\end{array}$ & kworb.net & 31,137 & 14.300 & 17.736 & 0 & 123 \\
\hline \multicolumn{8}{|c|}{ Time-specific controls } \\
\hline Re-enter & $\begin{array}{l}\text { Binary variable indicating if the song } \\
\text { re-enters the chart after a dropout. }\end{array}$ & Spotify Charts & 31,137 & 0.100 & 0.300 & 0 & 1 \\
\hline
\end{tabular}

Note: Release dates have been gathered from the Spotify API and cross-checked by the website Genius.com for robustness.

outside the Top 200 chart, we contend that such tracks are likely to exert less competitive pressure than those appearing in the chart, because the latter by definition represent the most popular tracks available on the platform at any given time. On average, a music track in the Top 200 competes with 10 other chart tracks released by different artists and around three tracks by the same artist. The final element of demand we measure in this study is the diffusion of each track on the Spotify Top 200 chart. We account for this diffusion by measuring the entry position for each track $i$, as well as the difference (in time) between the release date and the first entry into the Spotify chart. On average, a track enters at the position of 100 after a period of around 19 days following release.

In addition to the main factors related to the digitalization of music markets outlined above, we also control for a range of product-, artist-, and time-specific characteristics when modeling variations in the daily demand for individual music tracks consumed via streaming platforms. For example, tracks from different genres are likely to experience differing levels of consumer demand (Hammond, 2014; Lee, Boatwright, \& Kamakura, 2003). We have therefore collected the corresponding genre information from allmusic.com for each song listed in the Top 200 chart and classified it in the genre categories, Country, Electronic, Latin, Pop/Rock, R\&B, Rap, and Miscellaneous, to control for genre-specific effects. Although we are not aware of any literature that specifically analyzes variation in commercial performance of remixes, empirical evidence has shown that soundtracks may outperform nonsoundtracks (Bradlow \& Fader, 2001; Strobl \& Tucker, 2000). We therefore also control for track-level characteristics such as whether the tracks are remixes, soundtracks, or Christmas songs (Strobl \& Tucker, 2000). We also control for the type of track releases (i.e., compilation, single, and album) that has been classified by Spotify and collected from the Spotify API.

Differences in the commercial performance of music outputs have also been observed on the basis of the characteristics of the artists themselves, including gender, previous commercial success, and length of career (Fox \& Kochanowski, 2007; Hamlen, 1991), as well as between solo artists and groups (Bhattacharjee et al., 2007; Giles, 2007). Gender- and group-specific information for each artist is collected from allmusic.com, whereas the previous commercial success is based on a calculation with data from kworb.net. Our modeling approach controls for all of these factors.

Spotify has been growing considerably over our study period (De Silva, 2019). Thus, we include time controls (i.e., monthly dummy variables for more flexible trends) to capture and control for the effects of tracks entering our analysis at different points in our sample period. In addition, at least some tracks might enjoy multiple spells in the chart, especially as we follow them over a period of 37 months. As we assume time constancy surrounding the process affecting chart duration, we adopt a consecutive spell approach (see Blossfeld et al., 2009) to resolve tracks that re-enter the charts after previously dropping out. To further address the issue of tracks that may leave and re-enter the Spotify Global Top 200 chart during our observed period, we also include a binary variable indicating re-entries.

Equation 1 outlines our approach to measuring variations in demand. More specifically, we suggest that chart survival time of track $i$ at time $t$ is the function of the major label that distributed track $i$, 


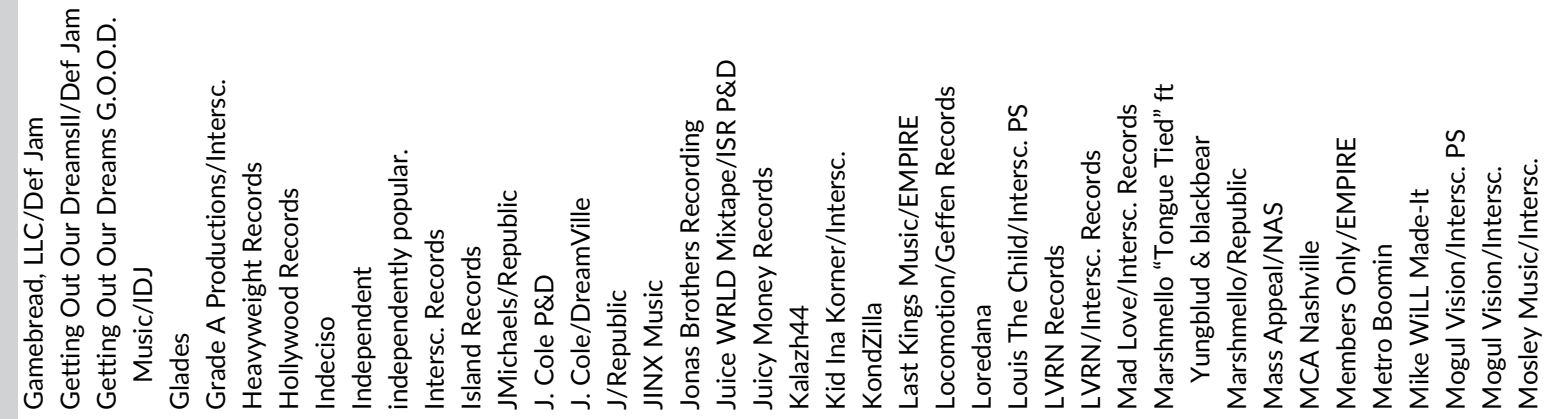

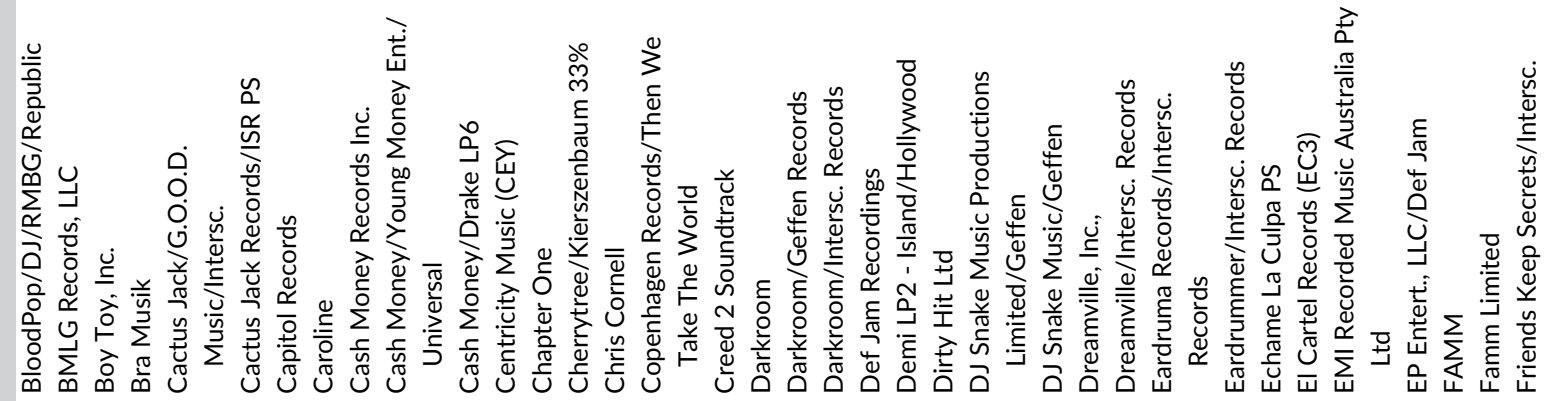

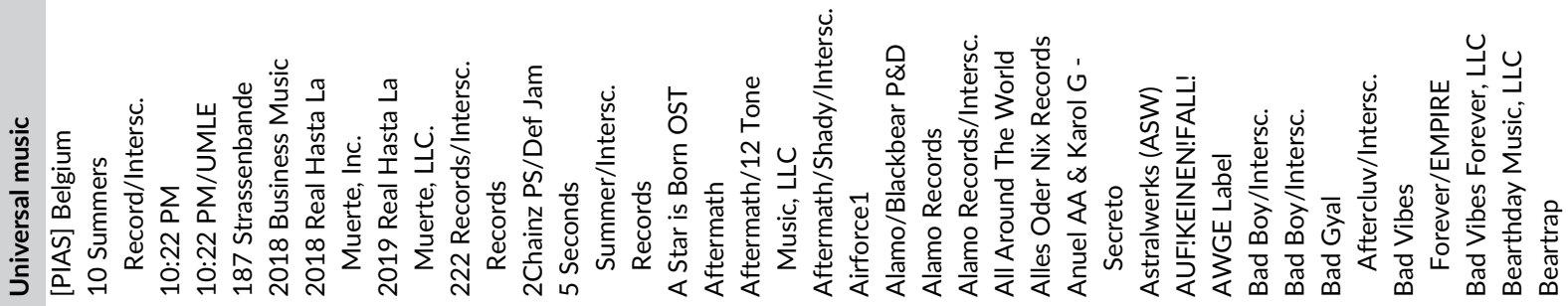

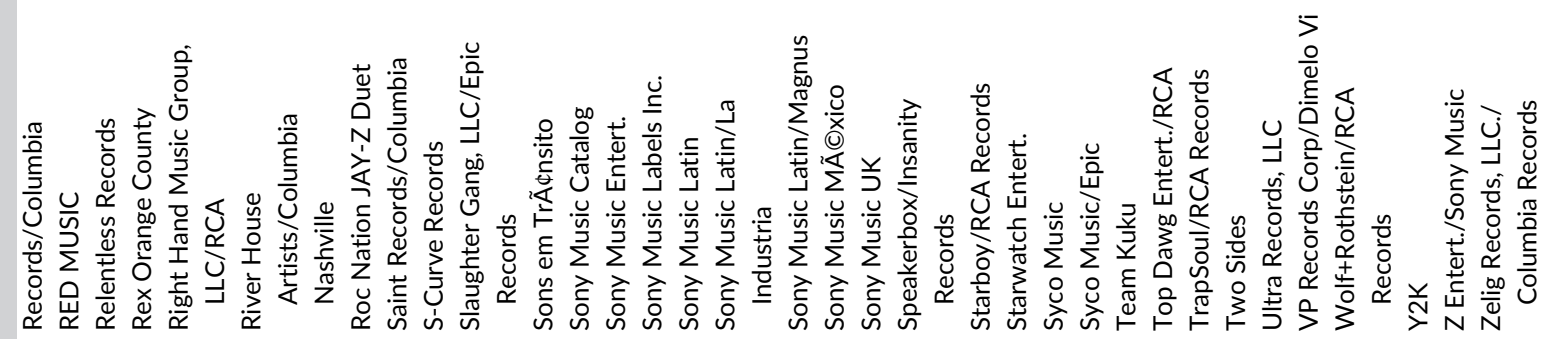

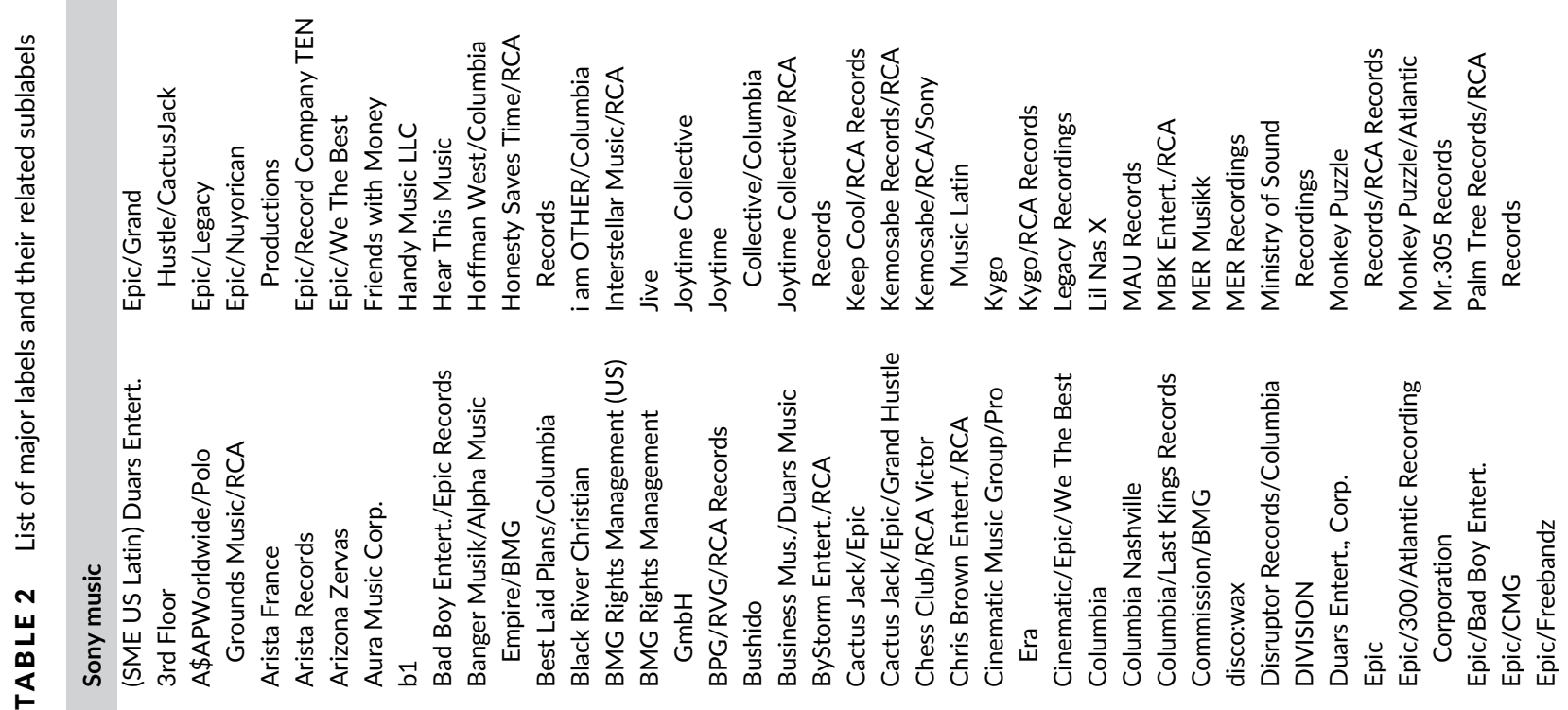


chart competition faced by track $i$ from other tracks $j$ by the same artist $a$ and other artists $o$ at time $t$, and the diffusion factors of track $i$ :

$$
\begin{aligned}
& \text { Chat Survival }{ }_{i t}=f\left(\text { Major Label }_{i}, \text { Chart Competition }_{\text {aoijt }}\right. \text {, } \\
& \text { Diffusion }, \text {, Product-specific controls }{ }_{i} \text {, Artist-specific } \\
& \text { controls }_{\text {aij }} \text {,Time-specific controls } s_{i t} \text { ), }
\end{aligned}
$$

where Chart Survival represents the cumulative number of days that track $i$ has spent in the Spotify Global Top 200 chart as of time $t$. Major Label is a variable representing track i's release by a major music label (i.e., Sony, Warner, or Universal). Chart Competition is a vector that includes measures of both internal and external chart competition for track $i$, measured in terms of the number of other Top 200 tracks $j$ by the same $a$ and other artists $o$ released over a rolling 7-day window, beginning in the observed week at time $t$. Diffusion represents a vector of variables containing track i's initial chart entry position, as well as the difference in the number of days between track $i$ 's release date and its first chart appearance. Product-specific controls is a vector containing controls for the musical genre (i.e., Country, Electronic, Latin, Pop/Rock, R\&B, Rap, and Miscellaneous), as well as whether the track $i$ is from a soundtrack, remix, Christmas album, compilation, or single or album release. Artist-specific controls is a vector of variables indicating if track $i$ has been performed by a band, duo, or female or male solo artist. This vector also includes a measure of the experience (career duration) of the artist $a$, calculated as the difference between the year of chart entry and the artist's first appearance in the music industry. Additionally, we control for prior success by accounting for the total number of previous songs $j$ of an artist $a$ before the appearance of track $i$ in the Global Spotify Top 200 charts. Time-specific controls is a vector representing a flexible monthly time trend and the re-entry of track $i$ at time $t$ in the charts after a previous dropout (if applicable).

We use survival analysis to model the amount of time (in days) each track spends within the streaming charts. In this context, the "failures" observed in our dataset refer to the disappearance of tracks from the streaming chart. Therefore, we declare a track to be a failure once it is no longer listed among the 200 topmost streamed tracks on the Spotify platform. We consider the survival function instead of the hazard rate to identify the determinants of streaming consumption. Survival time is considered a random variable $T$ with the distribution function $F(t)=\operatorname{Prob}(T \leq t)$. The associated survival function shows that the probability that a song continues to be listed in the charts is given by

$$
S(t)=1-F(t)=\operatorname{Prob}(T>t) .
$$

As $F$ is differentiable, the derivative or density function of the lifetime distribution is presented by

$$
f(t)=\frac{d}{d t} F(t)
$$

Consequently, the survival function can be expressed in the form of the density function: 


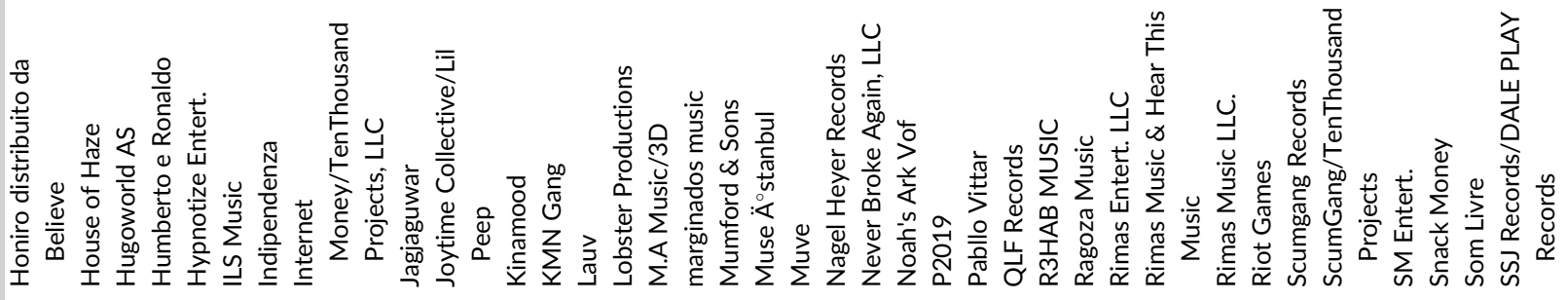

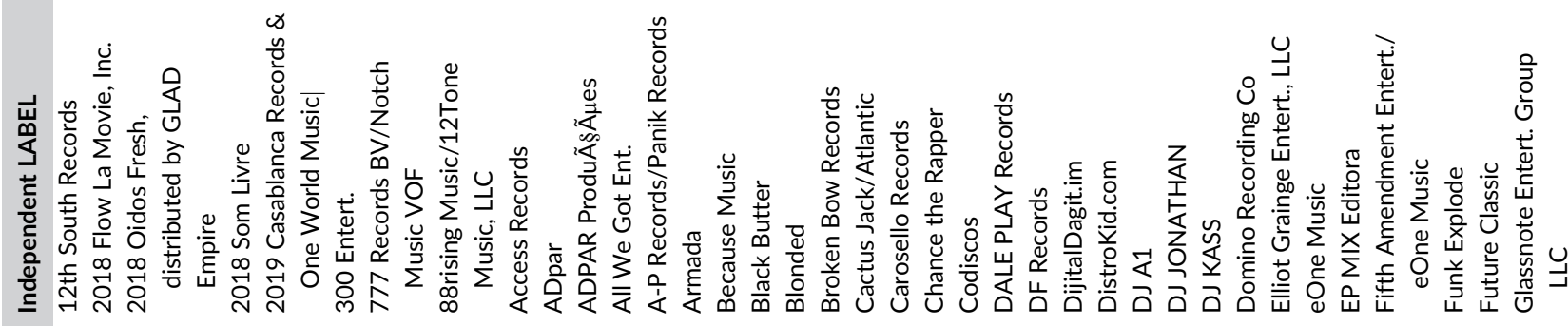

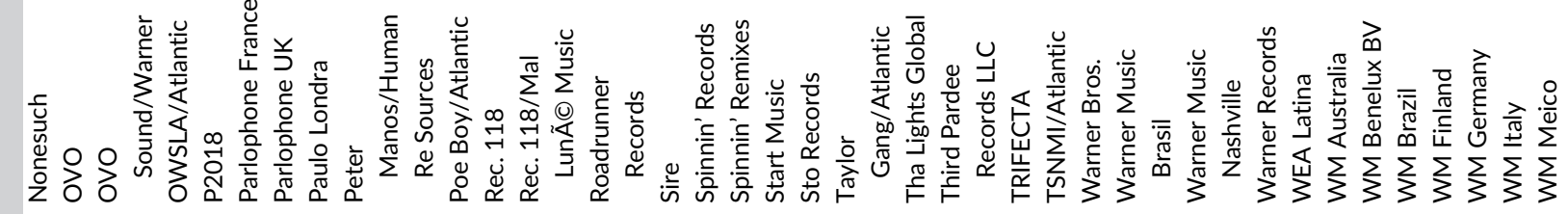

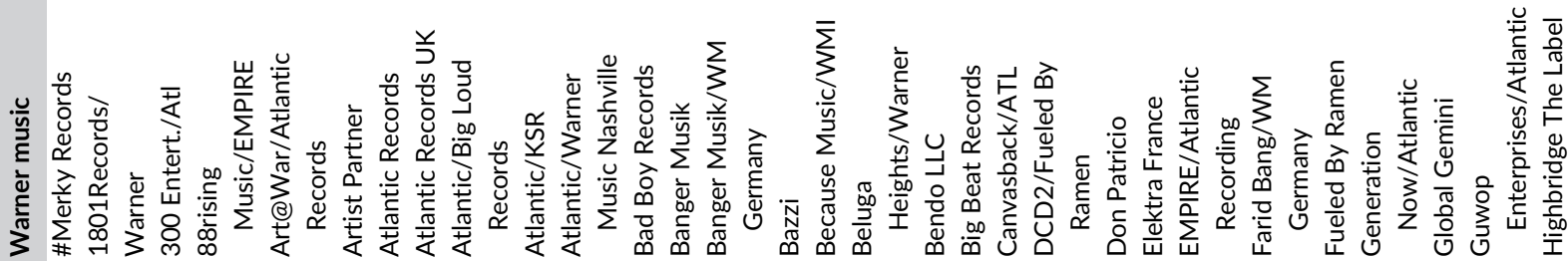

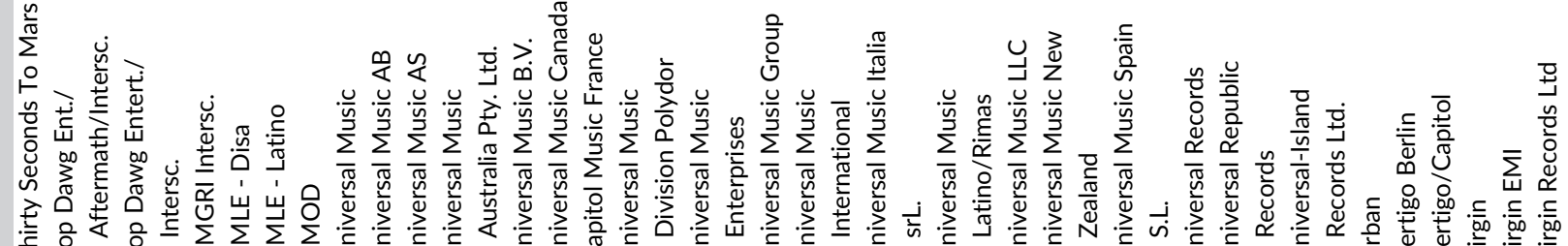

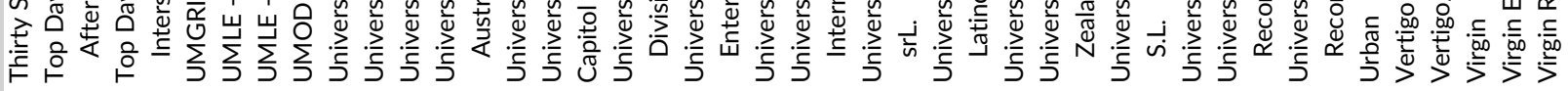

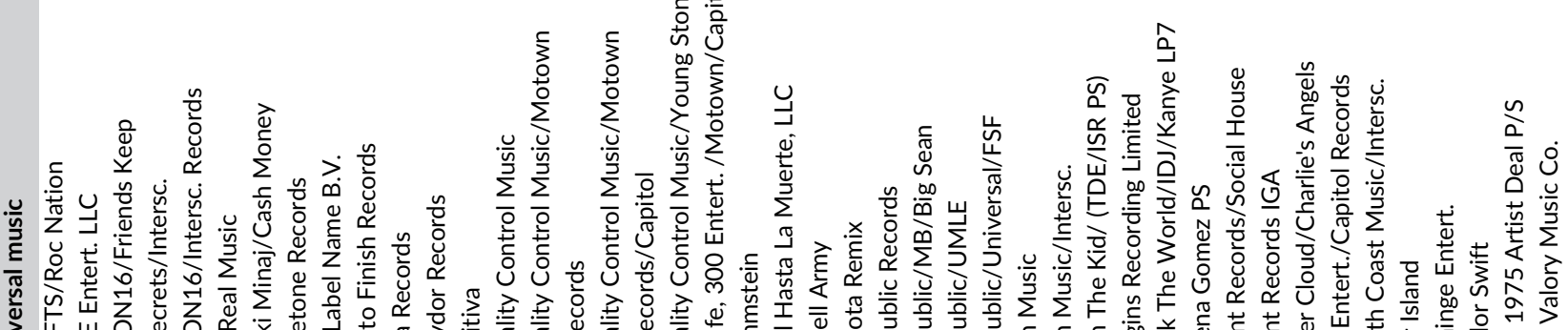

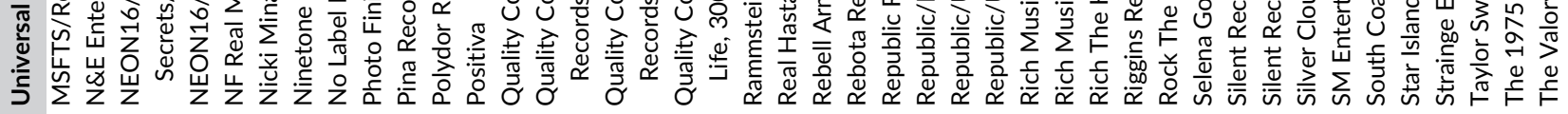

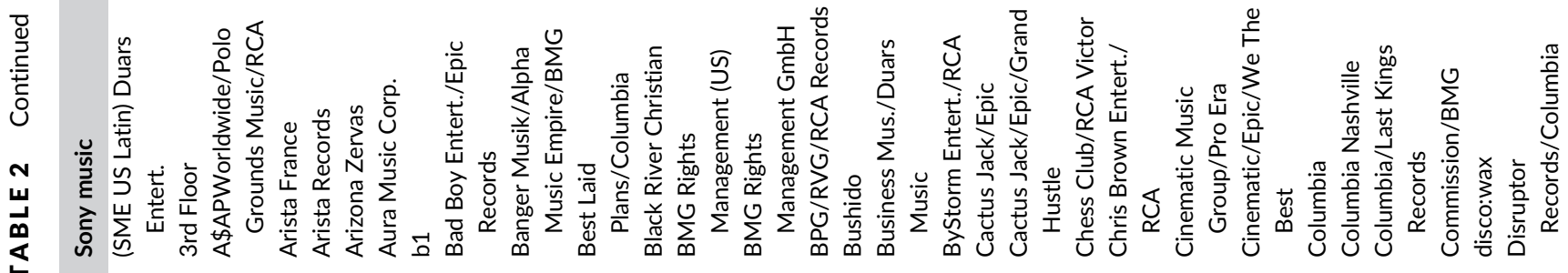




$$
S(t)=1-F(t)=\operatorname{Prob}(T>t)=\int_{t}^{\infty} f(u) d u
$$

A model for adjusting survival functions for the effects of covariates is the accelerated failure time (AFT) model. The AFT model applies the natural logarithm to the survival time logt and thus is expressed as a linear function of the covariates, leading to the linear model:

$$
\ln t=x \beta+\varepsilon,
$$

where $x$ is a vector of covariates, $\beta$ is a vector of regression coefficients, and $\varepsilon$ is the error with density $f()$. The distribution of the error term defines the regression model, with $f()$ fitted to normal, logistic or extreme-value densities corresponding to lognormal, log-logistic, or exponential/Weibull regressions, respectively. Previous studies adopting survival analysis in the context of entertainment industries have tended to use either the Weibull distribution (e.g., De Vany \& Walls, 1997; Deuchert, Adjamah, \& Pauly, 2005; Kaimann, Stroh-Maraun, \& Cox, 2018) or the exponential function (e.g., Kaimann et al., 2018; McKenzie, 2009). However, Clement, Fabel, and SchmidtStolting (2006) suggest that the diffusion of music over the product lifecycle necessitates the use of more flexible survival models and instead recommend the use of log-logistic models. We therefore present results from the log-logistic function alongside those from the exponential and Weibull specifications for comparison.

\section{5 | EMPIRICAL ANALYSIS}

We present the results from a number of duration models to explain variations in the total number of days that a track spends within the Top 200 global streaming chart. Owing to the use of similar variables capturing the determinants of music consumption, in Table 3 , we present correlation coefficients between the track survival time, music label, chart competition, and diffusion. Aside from the expected negative correlations between categorical variables (e.g., single vs. album releases), the results from Table 3 show that multicollinearity is not a significant concern. In addition, the variance inflation factor scores show that the inclusion of all determinants in the same model specification lead to an acceptable level of inflation of the coefficient estimates in comparison with a situation in which no linear relationship exists between predictor variables. The highest variance inflation factor values in any of the estimations do not exceed a value of 9, which is below the accepted threshold of 10 , whereby multicollinearity would significantly affect our results (Wooldridge, 2013, p. 94).

The results from the parametric survival models can be found in Table 4. Specifications I and II present the results from the Weibull and exponential models, respectively, whereas specification III presents the results from the log-logistic function. Coefficient estimates from the survival models represent time ratios derived from exponentiating the relevant regression coefficients and subtracting them by one. This leads to a percentage change in the expected survival time associated with a one unit increase in a covariate 
TABLE 3 Correlation matrix of demand measures

\begin{tabular}{|c|c|c|c|c|c|c|c|c|c|}
\hline & (1) & (2) & (3) & (4) & (5) & (6) & (7) & (8) & (9) \\
\hline (1) Survival time & 1 & & & & & & & & \\
\hline (2) Major label & 0.122 & 1 & & & & & & & \\
\hline (3) External chart competition & -0.009 & -0.025 & 1 & & & & & & \\
\hline (4) Internal chart competition & -0.214 & -0.032 & 0.215 & 1 & & & & & \\
\hline (5) Start position & -0.122 & -0.101 & -0.027 & -0.094 & 1 & & & & \\
\hline (6) Time to chart & 0.041 & -0.020 & -0.013 & -0.076 & 0.286 & 1 & & & \\
\hline (7) Album & 0.116 & 0.035 & 0.043 & 0.226 & -0.212 & -0.044 & 1 & & \\
\hline (8) Compilation & -0.017 & 0.021 & -0.016 & -0.024 & 0.076 & -0.005 & -0.098 & 1 & \\
\hline (9) Single & -0.113 & -0.039 & -0.040 & -0.222 & 0.198 & 0.045 & -0.982 & -0.091 & 1 \\
\hline
\end{tabular}

(Korosteleva, 2009). The Akaike information criterion and the log pseudolikelihood indicate a statistical preference for the log-logistic model, so we focus on results from Specification III when reporting our results. However, results of the log-logistic model are mostly consistent with those from the Weibull and exponential model and differ only in terms of a small number of product- and artist-specific controls, the majority of which are not statistically different from zero.

The distribution of our dependent variable is right-skewed (see Figure 1), as is typical for entertainment goods (Chung \& Cox, 1994). Therefore, it is possible that the presence of significant outliers (i.e., individual tracks with abnormally long survival times) might skew our results. To address this possibility, we winsorize our data at the 99th percentile and present the results using the preferred log-logistic survival analysis in Specification IV. However, the results obtained using the winsorized dataset are identical or very similar to those from Specification III. As a result, we conclude that the results from our initial analysis are unlikely to have been affected by the presence of significant outliers.

With respect to $\mathrm{H} 1$, the coefficient estimates related to major music labels suggest a positive and statistically significant difference in chart survival time in comparison with independents $\left(+34.9 \%^{* *}\right)$. As we have shown in the survival curve (see Figure 2), around $50 \%$ of all tracks leave the Top 200 chart after a period of 8 days. Based on this average survival time of 8 days, our survival analysis shows that major labels, in comparison with independent labels, extend the chart survival time by around 2.8 days. We therefore find empirical evidence in support of $\mathrm{H} 1$, given that major labels are found to be positively associated with chart longevity. This finding is expected given the historic dominance of major labels in the music industry (Bhattacharjee et al., 2007). With respect to $\mathrm{H} 2$, related to external and internal chart competition, the log-logistic model presented in Table 4 shows that the release of each additional chart track by the same artist during the same week (internal competition) associates negatively and significantly with the duration of chart survival for a given music track (by $-4.7 \%^{* * *}$ or around 0.38 days). By contrast, our coefficient estimates related to external chart competition suggest no significant relationship in the expected chart survival time of an individual track.
We therefore find only partial support for $\mathrm{H} 2$. With respect to $\mathrm{H} 3$ in relation to diffusion, the coefficient estimates corresponding to the chart entry position suggest that a better initial entry position (corresponding to a "lower" starting position number, as entering the charts at number 1 is better than entering at number 200) tends to be associated with a highly significant increase in expected chart survival of around 0.13 days. However, we also find that a longer delay between the release of a track and its first chart entry tends to be associated with a statistically significant increase in the expected survival time of a song in the streaming charts $\left(+0.5 \%^{* * *}\right.$ or 0.04 days). Our findings therefore offer only partially support $\mathrm{H} 3$, given that they show that the chart survival of a particular track varies positively with both a high initial entry position and the amount of time between release and chart entry.

In addition to considering the vectors of variables that relate explicitly to our research hypotheses, our analysis also includes a number of product-specific and artist-specific characteristics in the model specifications presented in Table 4. Coefficient estimates show that the genres "Latin" $\left(+448.3 \%^{* * *}\right)$ and "R\&B" $\left(+61.8 \%^{* *}\right)$ associate with significantly longer survival times in comparison with the reference category "Country." In addition, soundtracks $\left(+124.6 \%^{* *}\right)$ also tend to be positively associated with chart survival, whereas single releases $\left(+164.4 \%^{* * *}\right)$ are also found to be significantly and positively associated with chart survival time in comparison with the reference category "album." Control variables capturing artist-specific characteristics show that both duos $(+46 \%$ ${ }^{*}$ ) and solo artists (female: $+61.3 \%^{* * *}$; male: $+45.5 \%^{* * *}$ ) tend to enjoy significantly longer chart survival times than groups. Additionally, the duration of an artist's career is shown to be associated with a slight reduction in chart survival time $\left(-2.7 \%^{* * *}\right)$, which implies that industry experience has a limited impact on the longevity of an artist's output in the streaming charts and possibly a preference among consumers for tracks released by newer acts. This contention is underpinned by the relatively small coefficients estimated for the previous success $\left(-0.4 \%^{*}\right)$ variable.

Overall, our results help shed considerable light on the determinants of music consumption via digital streaming platforms and the 
TABLE 4 Survival model specifications for chart survival time

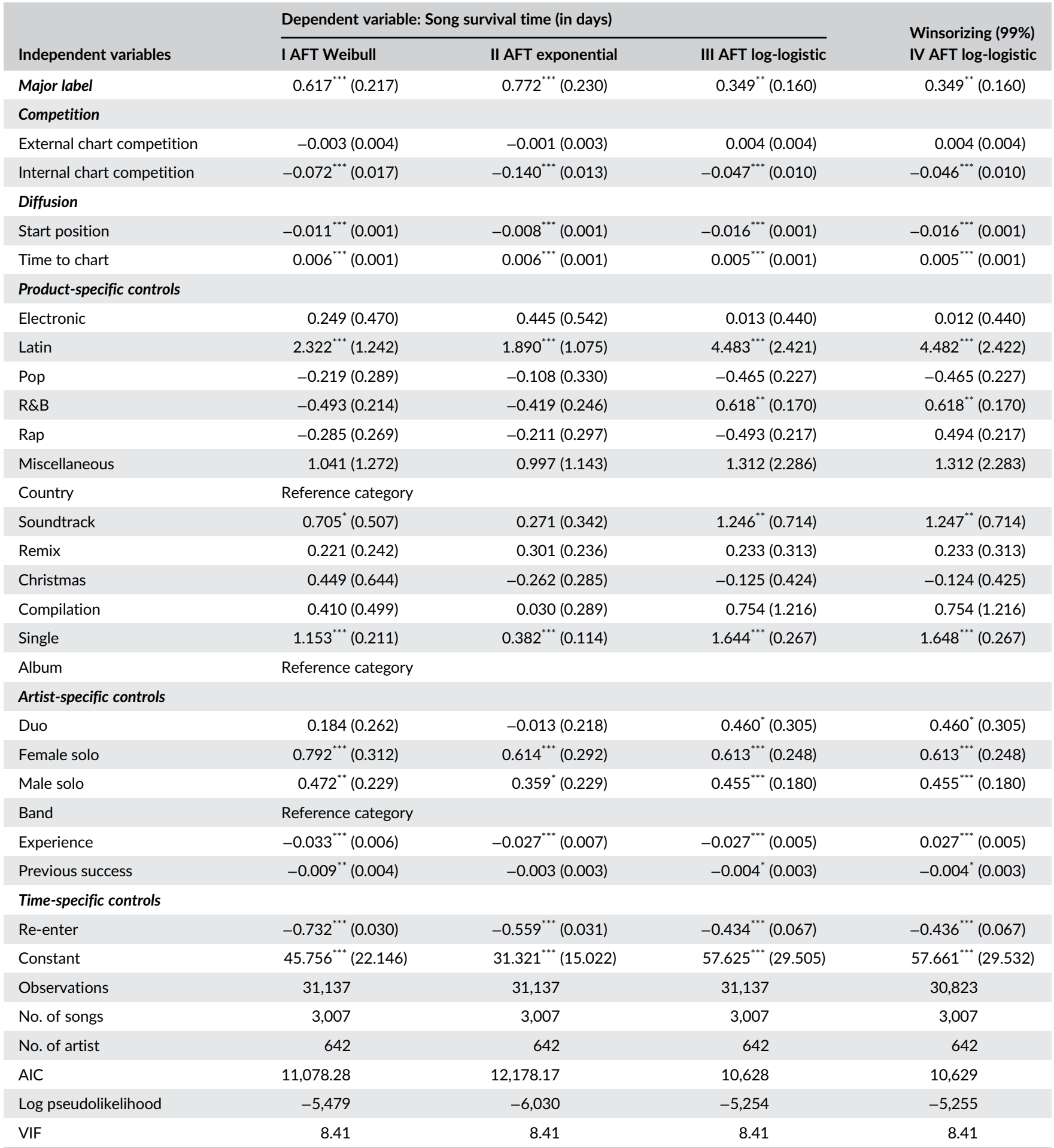

Note: Robust standard errors clustered by artist in parentheses. Coefficient of the AFT models standardized by e $\beta-1$. Flexible monthly time trend included. Abbreviations: AIC, Akaike information criterion; VIF, variance inflation factor.

* $p<.1$.

${ }^{* *} p<.05$.

${ }^{* * *} p<.01$.

factors that associate with variations in chart survival. Our findings lead us to accept $\mathrm{H} 1$ in relation to the positive association between chart survival and the involvement of a major label. However, we find only partial support for $\mathrm{H} 2$ with respect to internal (but not external) chart competition, as well as for $\mathrm{H} 3$ with respect to the pattern of diffusion. 


\section{6 | DISCUSSION}

The results of our study have several important managerial implications for music industry stakeholders. First, our results highlight how the "internal" competition between tracks appearing in the Top 200 that are released by the same artist tends to associate with shorter chart survival times. Although the absence of individual-level data precludes an assessment of the extent to which such tracks are true complements or substitutes, our results do suggest that multiple simultaneous releases by the same artist typically result in a degree of cannibalization of the chart survival times of each individual track. To provide a better understanding of the phenomenon of internal competition in the Top 200 charts, we conduct a simple back-of-theenvelope calculation based on our presented data and results. Given the above-mentioned average survival time of 8 days (see Figure 2), our survival analysis results show that each additional chart track released by the same artist is associated with a reduction in chart survival time of around 0.38 days (-4.7\%). Therefore, the release of one additional track associates with a decrease in the aggregated chart survival time of the entire portfolio of 0.75 days. Following the same rationale, two additional track releases by the same artist associate with a 2- to 26-day reduction in aggregate chart survival for the portfolio, whereas three additional tracks associate with a 4- to 51-day reduction in aggregated chart survival (see Table 5). Our findings therefore suggest that artists might be better off releasing a number of single tracks over time, rather than simultaneously, given that internal competition typically associates with a reduction of the aggregate number of weeks on the charts across the entire portfolio. As a result of pursuing such a strategy, the material from any one artist would not be forced to compete against itself to the same extent.

A greater focus on track-led consumption accords with recent industry evidence from the Recording Industry Association of America showing a $21 \%$ reduction in the value of album sales in the United

TAB LE 5 Back-of-the-envelope calculations of internal chart competition and aggregated chart survival

\begin{tabular}{|llll|}
$\begin{array}{l}\text { Number of } \\
\text { additional } \\
\text { tracks in the } \\
\text { charts from } \\
\text { the same artist }\end{array}$ & $\begin{array}{l}\text { Simple } \\
\text { aggregated } \\
\text { chart survival } \\
\text { time (in days) }\end{array}$ & $\begin{array}{l}\text { Reduced } \\
\text { aggregated chart } \\
\text { survival time } \\
\text { based on } \\
\text { survival model } \\
\text { specification (in } \\
\text { days) }\end{array}$ & $\begin{array}{l}\text { Difference } \\
\text { (in days) }\end{array}$ \\
\hline 1 & 16 & 15.25 & 0.75 \\
\hline 2 & 24 & 21.74 & 2.26 \\
\hline 3 & 32 & 27.49 & 4.51 \\
\hline 4 & 40 & 32.48 & 7.52 \\
\hline 5 & 48 & 36.72 & 11.28 \\
\hline 6 & 56 & 40.21 & 15.79 \\
\hline 7 & 64 & 42.94 & 21.06 \\
\hline 8 & 72 & 44.93 & 27.07 \\
\hline 9 & 80 & 46.16 & 33.84 \\
\hline 10 & 88 & 46.64 & 41.36 \\
\hline
\end{tabular}

States during 2019 in comparison with the previous year (Recording Industry Association of America, 2019). Our recommendation in this regard is also consistent with those of a number of other academic studies. For example, Im et al. (2019) show that the long-run consumption patterns on music streaming platforms tend to be concentrated more around a small number of "superstar" tracks, in comparison with download services. In addition, Hiller and Walter (2017) demonstrate that the adoption of a "hits" strategy on the part of artists leads to market deepening and the attraction of additional listeners in aggregate, whereas Essling et al. (2017) further demonstrate that releasing more singles with shorter intervals in between represents an effective means by which to capture consumer attention in the digital age. Thus, our findings lend indicative support to recommendations from elsewhere in the literature suggesting that artists should focus on releasing a smaller number of higher quality tracks.

By comparison, we find little or no evidence to suggest that chart survival times are affected by the degree of "external" chart competition faced by an individual music track. This finding implies that a greater amount of competition between new chart releases from other artists does not seem to cannibalize demand to the same extent as other chart materials released by the same artist. Acknowledging that artists and labels are not able to directly control the chart entry of any track, our findings nonetheless imply a preference for variety on the part of consumers. Record labels and streaming platforms that oversee large catalogs of material might therefore benefit from the release of a smaller range of new outputs from a larger number of artists at any given time, especially among the material that might be considered most likely to reach the Top 200 chart.

Our findings related to both internal and external chart competitions are unique and may result from the way in which such variables are measured by other authors. Previous studies (e.g., Im et al., 2018) tend to define competition in highly aggregated terms, such as by controlling for the total number of albums released each year. By contrast, we measure the number of competing tracks appearing in the Top 200 chart by the same and other artists released over a narrower (weekly) time period. Although the total number of albums released per year appears to exhibit no significant association with chart survival time (Bhattacharjee et al., 2007), we find that the number of competing chart tracks released in the same week by the same artist associates with a significant reduction. This finding implies that the nature of "internal" and "external" chart competition faced by music artists may be quite different in terms of their association with chart performance. It may be that the increased focus placed upon single tracks by online streaming services accounts for contrasting findings in this regard. If this is indeed the case, our results further speak to the nature of music consumption following the transition to digital streaming platforms.

In relation to the pattern of diffusion, our results highlight the benefits of higher initial entry on chart longevity. The greater chart longevity we observe for tracks achieving a better starting position may be indicative of a bandwagon effect, whereby market participants follow the cues of others and consume a particular cultural output simply because they observe others doing so (Leibenstein, 1950). In turn, this phenomenon leads to a concentration of market output 
around a disproportionately small number of "superstar" artists (Adler, 1985, 2006). Again, acknowledging that consumer listening patterns cannot be directly controlled, our findings in this regard imply that actions taken to influence the initial pattern of diffusion might be beneficial in terms of chart longevity. Such influence could be achieved, for example, by concentrating promotional efforts during the period immediately following release so as to benefit as much as possible from potential bandwagon effects. By contrast, the reduced longevity we observe for tracks that take less time to reach the charts is unique in the literature, although it somewhat contradicts our expectations. The finding may reflect a degree of information asymmetry, whereby consumers are unaware which tracks from popular artists are new or old (Hendricks \& Sorensen, 2009). The result may also be symptomatic of a "slow burn" on the part of certain tracks that build in popularity steadily over time, remaining in the charts for longer periods than tracks that reach the charts more quickly and "fizzleout" over a shorter period.

Finally, it is worth highlighting our finding that the backing of a major label associates significantly and positively with the duration of chart survival. This particular finding contradicts the results of Im et al. (2018), although is somewhat consistent with expectations given the market power enjoyed by major labels in conventional music markets. Although we cannot comment on the extent to which the market dominance of record labels might have changed following the introduction of streaming services, our results imply that tracks released by major labels are associated with improved chart performance, as previously indicated in studies of conventional markets (e.g., Bhattacharjee et al., 2007). Thus, a managerial implication of our study is that artists are likely to benefit from associating with a major label where possible. Of course, in practice, not all artists will have the luxury of this choice, as representation by a major label cannot be bought and needs to be earned. However, on the basis of our findings, artists already signed to a major label may wish to carefully consider whether it is in fact optimal to move to an independent label or to pursue a strategy of self-representation.

\section{1 | Limitations and directions for further study}

Despite the range of unique results and recommendations outlined by this study, our work suffers from several limitations. One of our key findings relates to the impact of internal chart competition and the related recommendation to release a smaller number of higher quality single racks in order to avoid self-cannibalization. Alternatively, it may be the case that wider "album-type" release strategies result in positive spill-over effects, for example, by increasing exposure to other material outside the charts. As such, it may be that although the chart survival of any individual track might be shorter in the presence of greater internal chart competition, the aggregate number of streams across an artist's entire (nonchart) catalog might be larger. In addition, our exclusive focus on the Top 200 means that we do not account for potential competition from tracks outside this chart. Unfortunately, our data do not allow us to formally address either of these issues.
Nonetheless, we focus on this homogeneous group of the most popular tracks and artists as the relationship between the musical, cultural, and societal impact of top musicians attracts enormous attention and has a disproportional impact on media and pop culture. Media outlets report on the performance of musicians in the charts, and the ranking and positions in the charts attract considerable public attention. Thus, the way in which tracks and artists are positioned and compete against each other in the charts sheds light on the consumption patterns of a global audience. However, future studies may benefit from gathering data on the consumption across an entire online streaming catalog rather than limiting their analysis to the subset of the Top 200 tracks as we have done. Doing so would allow for a more detailed analysis to be undertaken in relation to the net costs and benefits associated with greater levels of internal and external competition.

Additionally, our study is limited due to our inability to control for the unobservable quality of individual music tracks. Although quality represents an inherently subjective characteristic that is difficult to quantify, it may nevertheless impact our findings in a number of ways. For example, although major labels possess the significant resources required for the production, distribution, and promotion of new music, they may also be disproportionately likely to sign higher quality artists that have a greater chance of achieving commercial success (Benner \& Waldfogel, 2016). Major labels may also strategically decide which artists and tracks to promote more prominently than others, for example, by assigning an extraordinary marketing budget to boost the upcoming chart entry. In addition, the relationship we observe between the entry position and survival time might be a consequence of unobservable track quality, given that better quality tracks might be disproportionately likely to enter the charts in higher positions. In either case, such arguments call into question whether the increases we observe in chart survival times for major labels or initial entry positions are either causal or ultimately driven by the underlying quality of the artist(s). Unfortunately, we are neither able to introduce an independent and objective control for the inherent quality of each individual track nor fortunate enough to possess a suitable instrument to address concerns of potential endogeneity. If possible, future studies are encouraged to take further steps to address the issues of identification and causality in exploring similar relationships in the context of music consumption.

A further limitation of our study is that our dataset does not allow us to separate between first and subsequent streams by individual consumers. The consumption of music is typically characterized by repeat consumption, which increases utility up to a certain saturation level (Stigler \& Becker, 1977). As argued previously, the issue of repeat consumption is particularly important in the context of digital streaming platforms given that royalties are paid on a per-stream rather than a one-off basis. Future studies may therefore wish to examine issues such as whether there are differences in the factors influencing first and repeat streams. The data used in this study also follow a hierarchical structure, which can be clustered within artists, albums, and individual song titles. Future studies could overcome this limitation by adopting a multilevel model for survival analysis with random effects, where each first-level unit (i.e., a track) is nested in one second-level unit (i.e., an album), which in turn is nested in one 
third-level unit (i.e., an artist), as per the arguments outlined in Austin (2017).

Spotify also features personalized recommendation systems and consumer-specific playlists, which help reduce the uncertainty associated with the search for new music. Spotify's playlists play a crucial role in discovering new music and thus in promoting tracks to appear in the Top 200 streaming charts (Iqbal, 2019). Our present study has not controlled for the role potentially played by including individual tracks in particular playlists outside the Top 200 chart. Future studies could further analyze data on consumer behavior over a longer horizon to explore how recommendation systems and the role of playlists might affect consumer behavior over time. The point is particularly relevant given the rapidly changing digital landscape and the role played by signals of quality in overcoming information asymmetries.

Finally, it should be noted that the 37 months of observations used in our study make it difficult to directly compare our findings with those using longer sample periods, and any attempts to do so must be interpreted with caution. Although they are still in a relative infancy, it seems reasonable to expect that online streaming services will remain a popular channel for music consumption for many years to come. Although we feel that analyzing more than 3 years of data is sufficient to demonstrate the determinants of track popularity in the current environment, future studies may benefit from studying chart survival over a longer time horizon. In doing so, it would be possible to understand how the nature of music consumption and the characteristics of popular tracks might change as online streaming enters a period of sustained market maturity.

\section{7 | CONCLUSION}

This study undertakes a large-scale empirical analysis of the demand for music tracks consumed via digital streaming platforms. Specifically, we investigate the factors that are associated with variations in chart survival time, which we argue represents a strategically important outcome within the commercial music industry. We identify a number of market characteristics and traits (i.e., major label, chart competition, and diffusion) that are relevant to digital streaming platforms and use these to explain variations in the chart survival of individual tracks. Our empirical analysis suggests that support from major music labels tends to associate with longer chart survival, whereas elements of chart competition and diffusion also strongly associate with variations in chart longevity.

The unique set of findings outlined above allows us to make a number of important managerial recommendations of relevance to music industry stakeholders. Our findings showing the influence from major music labels on chart survival indicates that their involvement associates positively with chart longevity on digital streaming platforms. Those artists in a position to make such a decision might therefore consider finding or retaining the support of a major label if possible, rather than looking towards independent labels or even releasing their material directly to music streaming platforms. Further, the ease with which consumers can switch tracks when listening to music via digital streaming imposes relatively low switching and opportunity costs, which in turn results in an increase in competition for attention both between and within the catalogs of different artists. Our analysis demonstrates that chart competition between tracks from the same artist can result in a degree of self-cannibalization of consumer attention, thus supporting a strategy of fewer, higher quality tracks by each artist at any given time. Finally, our study highlights how a higher initial entry position represents one of the most relevant factors affecting both chart survival and aggregate streaming volumes. This finding highlights the importance of promotional activities in the period leading to and immediately following the release of new material. Overall, our findings offer considerable insights into the nature of music consumption given the highly disruptive influence that online streaming services have had upon the industry (Aguiar \& Waldfogel, 2016; Hiller, 2016).

\section{ACKNOWLEDGEMENTS}

This work was partially supported by the German Research Foundation (DFG) within the Collaborative Research Centre 901 "On-The-Fly Computing" under the project 160364472-SFB901. The authors declare that they have no conflict of interest.

\section{DATA AVAILABILITY STATEMENT}

The data that support the findings of this study are available from the corresponding author upon reasonable request.

\section{ORCID}

Daniel Kaimann (D) https://orcid.org/0000-0001-8430-2310

Joe Cox (D) https://orcid.org/0000-0001-7806-1194

\section{REFERENCES}

Adler, M. (1985). Stardom and talent. American Economic Review, 75(1), 208-212.

Adler, M. (2006). Stardom and talent. In Handbook of the Economics of Art and Culture (Vol. 1) (pp. 895-906). https://doi.org/10.1016/S15740676(06)01025-8

Aguiar, L., \& Waldfogel, J. (2016). Even the losers get lucky sometimes: New products and the evolution of music quality since Napster. Information Economics and Policy, 34, 1-15. https://doi.org/10.1016/j. infoecopol.2015.12.003

Aguiar, L., \& Waldfogel, J. (2018). As streaming reaches flood stage, does it stimulate or depress music sales? International Journal of Industrial Organization, 57, 278-307. https://doi.org/10.1016/j.ijindorg.2017. 06.004

Alexander, P. J. (1994). Entry barriers, release behavior, and multi-product firms in the music recording industry. Review of Industrial Organization, 9(1), 85-98. https://doi.org/10.1007/BF01024221

Asai, S. (2009). Sales patterns of hit music in Japan. Journal of Media Economics, 22(2), 81-101. https://doi.org/10.1080/ 08997760902900106

Austin, P. C. (2017). A tutorial on multilevel survival analysis: Methods, models and applications. International Statistical Review, 85(2), 185-203. https://doi.org/10.1111/insr.12214

Bakos, Y., \& Brynjolfsson, E. (2000). Bundling and competition on the Internet. Marketing Science, 19(1), 63-82. https://doi.org/10.1287/ mksc.19.1.63.15182

Benner, M. J., \& Waldfogel, J. (2016). The song remains the same? Technological change and positioning in the recorded music industry. Strategy Science, 1(3), 129-147. https://doi.org/10.1287/stsc.2016.0012 
Bhattacharjee, S., Gopal, R. D., Lertwachara, K., \& Marsden, J. R. (2006). Consumer search and retailer strategies in the presence of online music sharing. Journal of Management Information Systems, 23(1), 129-159. https://doi.org/10.2753/MIS0742-1222230104

Bhattacharjee, S., Gopal, R. D., Lertwachara, K., Marsden, J. R., \& Telang, R. (2007). The effect of digital sharing technologies on music markets: A survival analysis of albums on ranking charts. Management Science, 53 (9), 1359-1374. https://doi.org/10.1287/mnsc.1070.0699

Blossfeld, H. P., Golsch, K., \& Rower, G. (2009). Event history analysis with Stata (First ed.). Psychology Press.

Bockstedt, J. C., Kauffman, R. J., \& Riggins, F. J. (2006). The move to artistled on-line music distribution: A theory-based assessment and prospects for structural changes in the digital music market. International Journal of Electronic Commerce, 10(3), 7-38. https://doi.org/10.2753/ JEC1086-4415100301

Borghi, M., Maggiolino, M., Montagnani, M. L., \& Nuccio, M. (2012). Determinants in the online distribution of digital content: An exploratory analysis. European Journal for Law and Technology, 3(2), 1-29.

Bradlow, E. T., \& Fader, P. S. (2001). A Bayesian lifetime model for the "Hot 100" Billboard songs. Journal of the American Statistical Association, 96(454), 368-381. https://doi.org/10.1198/ 016214501753168091

Brynjolfsson, E., Hu, Y., \& Simester, D. (2011). Goodbye pareto principle, hello long tail: The effect of search costs on the concentration of product sales. Management Science, 57(8), 1373-1386. https://doi.org/10. $1287 / \mathrm{mnsc} .1110 .1371$

Che, Y. K., \& Hörner, J. (2017). Recommender systems as mechanisms for social learning. Quarterly Journal of Economics, 133(2), 871-925.

Chen, L., \& King, R. C. (2017). To lend is to own: A game theoretic analysis of the e-book lending market. International Journal of Electronic Commerce, 21(3), 334-362. https://doi.org/10.1080/10864415.2016. 1319214

Chung, K. H., \& Cox, R. A. (1994). A stochastic model of superstardom: An application of the Yule distribution. The Review of Economics and Statistics, 76, 771-775. https://doi.org/10.2307/2109778

Clement, M., Fabel, S., \& Schmidt-Stolting, C. (2006). Diffusion of hedonic goods: A literature review. The International Journal on Media Management, 8(4), 155-163. https://doi.org/10.1207/ s14241250ijmm0804_1

Clemons, E. K., \& Lang, K. R. (2003). The decoupling of value creation from revenue: $A$ strategic analysis of the markets for pure information goods. Information Technology and Management, 4(2-3), 259-287. https://doi.org/10.1023/A:1022958530341

Connolly, M., \& Krueger, A. B. (2006). Rockonomics: The economics of popular music. In Handbook of the Economics of Art and Culture (Vol. 1) (pp. 667-719). https://doi.org/10.1016/S1574-0676(06)01020-9

Datta, H., Knox, G., \& Bronnenberg, B. J. (2018). Changing their tune: How consumers' adoption of online streaming affects music consumption and discovery. Marketing Science, 37(1), 5-21. https://doi.org/10. $1287 / \mathrm{mksc} .2017 .1051$

De Silva, M. (2019). Spotify is still the king of music streaming-for now. Retrieved from: https://qz.com/1736762/spotify-grows-monthlyactive-users-and-turns-profit-shares-jump-15-percent/

De Vany, A. S., \& Walls, W. D. (1997). The market for motion pictures: Rank, revenue, and survival. Economic Inquiry, 35(4), 783-797. https:// doi.org/10.1111/j.1465-7295.1997.tb01964.x

Deuchert, E., Adjamah, K., \& Pauly, F. (2005). For Oscar glory or Oscar money? Journal of Cultural Economics, 29(3), 159-176. https://doi.org/ 10.1007/s10824-005-3338-6

Dörr, J., Wagner, T. M., Hess, T., \& Benlian, A. (2013). Music as a service as an alternative to music piracy? An empirical investigation of the intention to use music streaming services. Business \& Information Systems Engineering, 5(6), 383-396.5. https://doi.org/10.1007/s12599-0130294-0
Elberse, A. (2010). Bye-bye bundles: The unbundling of music in digital channels. Journal of Marketing, 74(3), 107-123. https://doi.org/10. 1509/jmkg.74.3.107

Elliott, C., \& Simmons, R. (2011). Factors determining UK album success. Applied Economics, 43(30), 4699-4705. https://doi.org/10.1080/ 00036846.2010 .498349

Essling, C., Koenen, J., \& Peukert, C. (2017). Competition for attention in the digital age: The case of single releases in the recorded music industry. Information Economics and Policy, 40, 26-40. https://doi.org/10. 1016/j.infoecopol.2017.05.002

Fox, M. A., \& Kochanowski, P. (2007). Multi-stage markets in the recording industry. Popular Music and Society, 30(2), 173-195. https://doi.org/ 10.1080/03007760701267714

Giles, D. E. (2007). Survival of the hippest: Life at the top of the hot 100. Applied Economics, 39(15), 1877-1887. https://doi.org/10.1080/ 00036840600707159

Gloor, S. (2011). Just how long is your "fifteen minutes?" An empirical analysis of artists' time on the popular charts. MEIEA Journal, 11(1), 61-83. https://doi.org/10.25101/11.3

Gopal, R. D., Ramesh, R., \& Whinston, A. B. (2003). Microproducts in a digital economy: Trading small, gaining large. International Journal of Electronic Commerce, 8(2), 9-30. https://doi.org/10.1080/10864415. 2003.11044292

Graham, G., Burnes, B., Lewis, G. J., \& Langer, J. (2004). The transformation of the music industry supply chain: A major label perspective. International Journal of Operations \& Production Management, 24(11), 1087-1103. https://doi.org/10.1108/01443570410563241

Hamlen, W. A. Jr. (1991). Superstardom in popular music: Empirical evidence. The Review of Economics and Statistics, 73, 729-733. https:// doi.org/10.2307/2109415

Hammond, R. G. (2014). Profit leak? Pre-release file sharing and the music industry. Southern Economic Journal, 81(2), 387-408. https://doi.org/ 10.4284/0038-4038-2013.059

Hendricks, K., \& Sorensen, A. (2009). Information and the skewness of music sales. Journal of Political Economy, 117(2), 324-369. https://doi. org/10.1086/599283

Hiller, R. S. (2016). Sales displacement and streaming music: Evidence from YouTube. Information Economics and Policy, 34, 16-26. https://doi. org/10.1016/j.infoecopol.2015.12.002

Hiller, R. S., \& Walter, J. M. (2017). The rise of streaming music and implications for music production. Review of Network Economics, 16(4), 351-385. https://doi.org/10.1515/rne-2017-0064

Hinz, O., Eckert, J., \& Skiera, B. (2011). Drivers of the long tail phenomenon: An empirical analysis. Journal of Management Information Systems, 27(4), 43-70. https://doi.org/10.2753/MIS0742-1222270402

Huang, C. Y. (2005). File sharing as a form of music consumption. International Journal of Electronic Commerce, 9(4), 37-55. https://doi.org/10. 1080/10864415.2003.11044343

International Federation of the Phonographic Industry. (2020). Global Music Report: The Industry in, 2019. Retrieved from: https://ifpi.org/ news/en

Im, H., Song, H., \& Jung, J. (2018). A survival analysis of songs on digital music platform. Telematics and Informatics, 35(6), 1675-1686. https:// doi.org/10.1016/j.tele.2018.04.013

Im, H., Song, H., \& Jung, J. (2019). The effect of streaming services on the concentration of digital music consumption. Information Technology \& People, 33(1), 160-179. https://doi.org/10.1108/ITP-12-2017-0420

Iqbal, N. (2019). Forget the DJs: Spotify playlists are the new musical starmakers. Retrieved from: https://www.theguardian.com/music/ 2019/apr/28/streaming-music-algorithms-spotify

Kaimann, D., Stroh-Maraun, N., \& Cox, J. (2018). A duration model analysis of consumer preferences and determinants of video game consumption. Journal of Consumer Behaviour, 17(3), 290-301. https://doi.org/ 10.1002/cb.1711 
Klein, C. C., \& Slonaker, S. W. (2010). Chart turnover and sales in the recorded music industry: 1990-2005. Review of Industrial Organization, 36(4), 351-372. https://doi.org/10.1007/s11151-010-9250-z

Klein, B., Meier, L. M., \& Powers, D. (2017). Selling out: Musicians, autonomy, and compromise in the digital age. Popular Music and Society, 40 (2), 222-238. https://doi.org/10.1080/03007766.2015.1120101

Korosteleva, O. (2009). Clinical statistics: Introducing clinical trials, survival analysis, and longitudinal data analysis. Jones \& Bartlett Publishers.

Koukova, N. T., Kannan, P. K., \& Ratchford, B. T. (2008). Product form bundling: Implications for marketing digital products. Journal of Retailing, 84(2), 181-194. https://doi.org/10.1016/j.jretai.2008.04.001

Lang, K., Shang, R., \& Vragov, R. (2015). Consumer co-creation of digital culture products: Business threat or new opportunity? Journal of the Association for Information Systems, 16(9), 766-798.

Lee, J., Boatwright, P., \& Kamakura, W. A. (2003). A Bayesian model for prelaunch sales forecasting of recorded music. Management Science, 49(2), 179-196. https://doi.org/10.1287/mnsc.49.2.179.12744

Leibenstein, H. (1950). Bandwagon, snob, and Veblen effects in the theory of consumers' demand. The Quarterly Journal of Economics, 64(2), 183-207. https://doi.org/10.2307/1882692

Li, H., Jain, S., \& Kannan, P. K. (2019). Optimal design of free samples for digital products and services. Journal of Marketing Research, 56(3), 419-438. https://doi.org/10.1177/0022243718823169

McKenzie, J. (2009). Revealed word-of-mouth demand and adaptive supply: Survival of motion pictures at the Australian box office. Journal of Cultural Economics, 33(4), 279-299. https://doi.org/10.1007/s10824009-9104-4

Mehrafshan, N., Goerke, B., \& Clement, M. (2016). The effect of unexpected chart positions on the firm value of music labels. An event study of album success. ECONSTOR Working Paper. Retrieved from http://hdl.handle.net/10419/142161

Moe, A. G., \& Earl, P. E. (2009). Bandwagon and reputation effects in the popular music charts. Queensland: University of Queensland.

Moreau, F. (2013). The disruptive nature of digitization: The case of the recorded music industry. International Journal of Arts Management, 15 (2), 18-31.

Mulligan, M. (2015). Awakening: The music industry in the digital age. London: MIDiA Research.

Mulligan, M. (2018). Mid-year 2018 streaming market shares. Retrieved from: http://www.midiaresearch.com/blog/mid-year-2018-streamingmarket-shares/

Naveed, K., Watanabe, C., \& Neittaanmäki, P. (2017). Co-evolution between streaming and live music leads a way to the sustainable growth of music industry-Lessons from the US experiences. Technology in Society, 50, 1-19. https://doi.org/10.1016/j.techsoc.2017. 03.005

Ordanini, A. (2006). Selection models in the music industry: How a prior independent experience may affect chart success. Journal of Cultural Economics, 30(3), 183-200. https://doi.org/10.1007/s10824-0069013-8

Ordanini, A., \& Nunes, J. C. (2016). From fewer blockbusters by more superstars to more blockbusters by fewer superstars: How technological innovation has impacted convergence on the music chart. International Journal of Research in Marketing, 33(2), 297-313. https://doi. org/10.1016/j.jijresmar.2015.07.006

Rangaswamy, A., \& Gupta, S. (2000). Innovation adoption and diffusion in the digital environment: some research opportunities. New Product Diffusion Models (1, pp. 75-98). New York: Springer Science+Business Media.

Recording Industry Association of America. (2019). Year-end 2019 RIAA music revenues report. Accessed via:https://www.riaa.com/wp-
content/uploads/2020/02/RIAA-2019-Year-End-Music-Industry-Revenue-Report.pdf

Ren, J., \& Kauffman, R. J. (2017). Understanding music track popularity in a social network. Proceedings of the 25th European Conference on Information Systems ECIS, Guimarães, Portugal, June 5-10. 374-388. Available at: https://ink.library.smu.edu.sg/sis_research/3960

Ren, J., \& Kauffman, R. J. (2018). Streaming music diffusion in a semiclosed social environment. Proceedings of the 2018 Pacific-Asia Conference on Information Systems, Yokohama, Japan, 2018 June 26-30. Available at: https://ink.library.smu.edu.sg/sis_research/4275

Schneider, L., \& Gros, C. (2019). Five decades of US, UK, German and Dutch music charts show that cultural processes are accelerating. Royal Society Open Science, 6(8), 1-15. https://doi.org/10.1098/rsos. 190944

Steininger, D. M., \& Gatzemeier, S. (2019). Digitally forecasting new music product success via active crowdsourcing. Technological Forecasting and Social Change, 146, 167-180. https://doi.org/10.1016/j.techfore. 2019.04.016

Smith, E., \& Wingfield, N. (2008). More artists steer clear of iTunes. The Wall Street Journal. https://www.wsj.com/articles/ SB121987440206377643

Stigler, G. J., \& Becker, G. S. (1977). De gustibus non est disputandum. The American Economic Review, 67(2), 76-90.

Strobl, E. A., \& Tucker, C. (2000). The dynamics of chart success in the UK pre-recorded popular music industry. Journal of Cultural Economics, 24 (2), 113-134. https://doi.org/10.1023/A:1007601402245

Tang, M. C., \& Yang, M. Y. (2017). Evaluating music discovery tools on Spotify: The role of user preference characteristics. Journal of Library \& Information Studies, 15(1), 1-16.

Thomes, T. P. (2013). An economic analysis of online streaming music services. Information Economics and Policy, 25(2), 81-91. https://doi.org/ 10.1016/j.infoecopol.2013.04.001

Tu, Y., \& Lu, M. (2006). An experimental and analytical study of on-line digital music sampling strategies. International Journal of Electronic Commerce, 10(3), 39-70. https://doi.org/10.2753/JEC1086-4415100302

Waldfogel, J. (2015). Digitization and the quality of new media products: The case of music. In Economic analysis of the digital economy (pp. 407-442). University of Chicago Press.

WINTEL. (2017). WINTEL worldwide independent market report 2017. Retrieved from: http://winformusic.org/files/WINTEL\%202017/ WINTEL\%202017.pdf

Wooldridge, J. M. (2013). Introductory econometrics: A modern approach South-Western: Fifth International Edition.

Yoo, B., \& Kim, K. (2012). Does popularity decide rankings or do rankings decide popularity? An investigation of ranking mechanism design. Electronic Commerce Research and Applications, 11(2), 180-191. https:// doi.org/10.1016/j.elerap.2011.12.007

Zwass, V. (2003). Electronic commerce and organizational innovation: Aspects and opportunities. International Journal of Electronic Commerce, 7(3), 7-37.

How to cite this article: Kaimann D, Tanneberg I, Cox J. "I will survive": Online streaming and the chart survival of music tracks. Manage Decis Econ. 2020;1-18. https://doi.org/10. 1002/mde.3226 